\title{
As representações da Saúde Bucal na mídia impressa*
}

Aline Guio Cavaca ${ }^{1}$

Victor Gentilli

Eliana Martins Marcolino ${ }^{3}$

Adauto Emmerich ${ }^{4}$

CAVACA, A.G. et al. Representations of Oral Health in the printed media. Interface Comunic., Saude, Educ., v.16, n.43, p.1055-68, out./dez. 2012.

This study aimed to understand how information on oral health is carried in the printed media in the state of Espírito Santo, Brazil. This was a qualitative study using content analysis on 66 articles relating to the subject that were carried in the newspapers A Gazeta and A Tribuna between March 2004 and June 2009. The empirical material originated seven analytical categories: accountability of the individual, extreme realities, popular image of dentists and their offices, pathologization of halitosis, aesthetic valuation, determinants of oral health and prevention and habits. The media's approach towards oral health cuts across a complex of social, cultural, political, biological and economic factors. This highlights the importance of communication in context with the interests of society. Thus, the communication may be interactive, with dialogue, and its critical power in education and health promotion may be explored, thereby consciously relaying consumerism in Oral Health.

Keywords: Oral Health. Healthcare communication. Mass media. Public Health.
Buscou-se compreender como as informações sobre Saúde Bucal são veiculadas pela mídia impressa no estado do Espírito Santo - Brasil, por meio de uma pesquisa qualitativa, com análise de conteúdo de 66 matérias relacionadas à temática, veiculadas no período de março de 2004 a junho de 2009, nos jornais A Gazeta e A Tribuna. O material empírico originou sete categorias analíticas: responsabilização do indivíduo; realidades extremas; imaginário popular do dentista e do consultório dentário; patologização da halitose; valorização estética; determinantes da saúde bucal; prevenção e hábitos. A abordagem midiática da saúde bucal perpassa uma complexidade de fatores sociais, culturais, políticos, biológicos e econômicos, que destaca a importância de uma comunicação contextualizada com os interesses da sociedade, que seja interativa e dialógica e explore sua potência crítica na educação e promoção da saúde, veiculando, de maneira consciente, o consumismo em Saúde Bucal.

Palavras-chave: Saúde Bucal. Comunicação em saúde. Meios de comunicação de massa. Saúde Pública.

\footnotetext{
Elaborado com base em Cavaca (2011) pesquisa aprovada pelo Comitê de Ética e Pesquisa da Universidade Federal do Espírito Santo.

${ }^{1}$ Escola Nacional de Saúde Pública Sérgio Arouca, Fundação Oswaldo Cruz (Ensp/ Fiocruz). Rua Genera Roca, n.38, apto. 102.

Tijuca, Rio de Janeiro, RJ, Brasil. 20.521-070. alineguica@hotmail.com

${ }^{2}$ Departamento de Comunicação Social Universidade Federal do Espírito Santo.

${ }^{3}$ Laboratório de Comunicação e Saúde,

Saúde, Instituto de Comunicação e Informação Científica e Tecnológica em Saúde, Fiocruz. ${ }^{4}$ Programa de Pós-graduação em Saúde Coletiva Universidade Federal do Espírito Santo.
} 


\section{Introdução}

O tema "saúde bucal" envolve uma reflexão que perpassa os limites da cavidade bucal. Pode ser entendida a partir de suas dimensões funcionais e estética, e, também, do contexto social, seus condicionantes e necessidades coletivas (Kovaleski, Freitas, Botazzo, 2006). Acrescenta-se a isso a concepção de bucalidade, a qual diz respeito à expressão dos trabalhos sociais da boca humana e sua articulação aos modos como se vive e atua na sociedade (Botazzo, 2006, 2000).

Sabe-se que os meios de comunicação têm, hoje, um grande papel na determinação dos pensamentos e comportamentos dos indivíduos, sendo uma das instituições mais eficazes de manutenção da hegemonia dos valores e práticas da sociedade atual (Bydlowski, Westphal, Bicudo Pereira, 2004). Entretanto, a comunicação de massa concebe uma importante função educativa, uma vez que grande parte dos conhecimentos indispensáveis à vida, como, por exemplo, as informações em saúde pública, chegam aos cidadãos de forma mediada (Gentilli, 2005).

Desse modo, a informação jornalística tem suma relevância no suprimento da necessidade social da informação. Porém, compreende-se que a notícia é um produto e, por conseguinte, é estruturada e comercializada como tal. Sendo assim, as matérias de saúde e saúde bucal não fogem a essa regra e, para potencializar essa lógica, são produtos que vendem consideravelmente bem e que, além disso, estimulam o consumo de outras mercadorias, bens e serviços (Bydlowski, Westphal, Bicudo Pereira, 2004).

Entende-se que um enfoque consumista compromete o desenvolvimento do potencial de promoção da saúde dos meios de comunicação, ao se distanciarem tanto dos problemas que realmente afligem a população quanto de sua causalidade múltipla (Xavier, 2005; Bydlowski, Westphal, Bicudo Pereira, 2004).

Alguns estudos abordam a divulgação midiática da saúde bucal identificando, no padrão de noticiabilidade da temática, uma subutilização do potencial educativo da mesma, além de uma persuasão quanto ao padrão estético ideal do sorriso, gerando um processo de alienação necessário ao estímulo ao consumo (Amorim, Beatrice, Vicente da Silva, 2006; Sinhorini, Garbin, Oliveira, 2005; Carvalho, Bicudo Pereira, 1994; Noguerol et al., 1992). Diante do exposto, este estudo objetiva compreender como as informações sobre saúde bucal são veiculadas na mídia impressa do Espírito Santo - Brasil, a fim de analisar se a potência midiática está explorando de forma crítica a educação, a promoção da saúde e o consumismo em saúde bucal.

\section{Metodologia}

Trata-se de uma pesquisa exploratória documental, com abordagem qualitativa, a qual considera o contexto do problema de estudo e ocupa-se mais com significados do que com a frequência dos fatos (Tobar, Yalour, 2001). Além disso, é o tipo de pesquisa indicada para estudos de comunicação com análise de documentos (Rozemberg, 2006). O material pesquisado foi composto por todas as matérias relacionadas à saúde bucal veiculadas entre março de 2004 e junho de 2009, nos jornais impressos diários de maior circulação no estado do Espírito Santo: A Gazeta e A Tribuna, onde a pauta de saúde bucal é frequente (Cavaca et al., 2012). O período selecionado, de cinco anos, possibilita a verificação do panorama de noticiabilidade da saúde bucal no estado e corresponde a uma época de muitos investimentos na área de saúde bucal no Brasil, tendo se destacado pelo desenvolvimento da Política Nacional de Saúde Bucal (PNSB - comumente chamada de Brasil Sorridente) do governo federal, iniciada em 2004 e desenvolvida até os dias atuais (Brasil, 2004).

Realizou-se um levantamento retrospectivo das matérias que apresentavam, em seu conteúdo, as seguintes palavras-chave: dentista, odontologia e saúde bucal. Tais descritores foram escolhidos por abrangerem significativamente a seleção de matérias que abordam, de alguma maneira, a saúde bucal em seu conteúdo.

Para coleta de dados do jornal A Tribuna, utilizou-se o banco de dados digital fornecido pelo jornal, enquanto a seleção das notícias foi feita por intermédio de um Programa de Busca Inteligente 
desenvolvido pelo Laboratório de Recuperação Inteligente da Informação da Universidade Federal do Espírito Santo (UFES). Tal programa utiliza a busca de informações baseada não apenas em palavraschave, mas considerando a semântica subjacente à consulta feita pelo usuário, resgatando a informação mediante sucessivas aproximações, o que facilita o processo de busca (Azevedo et al., 2005). Em relação às matérias do jornal $\mathrm{A}$ Gazeta, estas foram selecionadas por meio de programa de busca do próprio jornal, com as palavras-chave correspondentes à temática.

\section{Organização do material}

Totalizaram 392 as matérias publicadas acerca do foco em questão. Destas, 178 foram selecionadas no jornal A Gazeta e 214 no jornal A Tribuna. Tendo sido selecionados, os textos, após impressos em papel A4, foram identificados e numerados de acordo com o jornal veiculado e respectiva data de publicação.

Uma vez organizado, o material empírico foi submetido à análise de conteúdo temática, a qual consiste "[...] em descobrir os <<núcleos de sentido > > que compõem a comunicação e cuja presença, ou frequência de aparição, podem significar alguma coisa para o objetivo analítico escolhido" (Bardin, 2009, p.131, grifo da autora). A análise de conteúdo tem capacidade para produzir inferências de um texto focal para seu contexto social de maneira objetivada (Minayo, 2008). Pode, além disso, ser utilizada para detectar tendências e modelos na análise de critérios de noticiabilidade, enquadramentos e agendamentos na pesquisa jornalística, estabelecendo alguns parâmetros culturais implícitos e a lógica organizacional por trás das mensagens (Herscovitz, 2007; Shoemaker, Reese, 1996).

Dessa maneira, como preconizado por Bardin (2009), organizou-se a análise de conteúdo em três etapas básicas:

A pré-análise: é a fase de organização, a qual permite considerar as intuições e sistematizar as ideias iniciais. Iniciou-se pela leitura flutuante dos 392 documentos, por meio da qual se estabeleceu contato com o material e deixou-se invadir por impressões e orientações. Com base nisso, foram selecionados 95 textos. O corpus, composto pelos documentos eleitos para serem submetidos aos procedimentos analíticos, foi definido pela seleção das matérias dotadas de caráter educativo, atendendo-se às regras de exaustividade, representatividade, homogeneidade e pertinência defendidas por Bardin (2009) - totalizando 66 matérias (Figura 1).

A exploração do material: trata-se da aplicação sistemática das decisões tomadas na pré-análise, composta pela codificação e pela categorização do material. A unidade de registro selecionada foi "tema", que, em sua pluralidade, foi identificado no corpus, recortado dos textos dos periódicos e transcrito em uma grade de análise, sendo então classificado em categorias definidas com base nas peculiaridades das matérias.

O tratamento dos resultados, inferência e interpretação: emergiram da análise 14 categorias empíricas, que foram agrupadas por questões metodológicas e conceituais em sete categorias analíticas estruturantes dos resultados (Quadro 1). Assim, a análise dos materiais obtidos permitiu a interpretação das mensagens latentes dos artigos e as suas inferências, baseadas nas teorias propostas.

A pesquisa foi aprovada pelo Comitê de Ética em Pesquisa do Centro de Ciências da Saúde da UFES. A autorização formal para a realização da pesquisa foi concedida pelos jornais selecionados para tal fim.

\section{Resultados e discussão}

Verificou-se, com base nos resultados, uma grande variedade de assuntos relacionados à saúde bucal abordados nos periódicos capixabas. Tais temas foram extraídos do material empírico e agrupados em categorias, as quais foram segmentadas em subcategorias, sistematizadas e definidas de acordo com o Quadro 1. Cada uma delas será discutida, com o fim de se obter uma compreensão mais aprofundada da temática. 
Figura 1. Pré-análise do material empírico

\section{PRÉ-ANÁLISE}

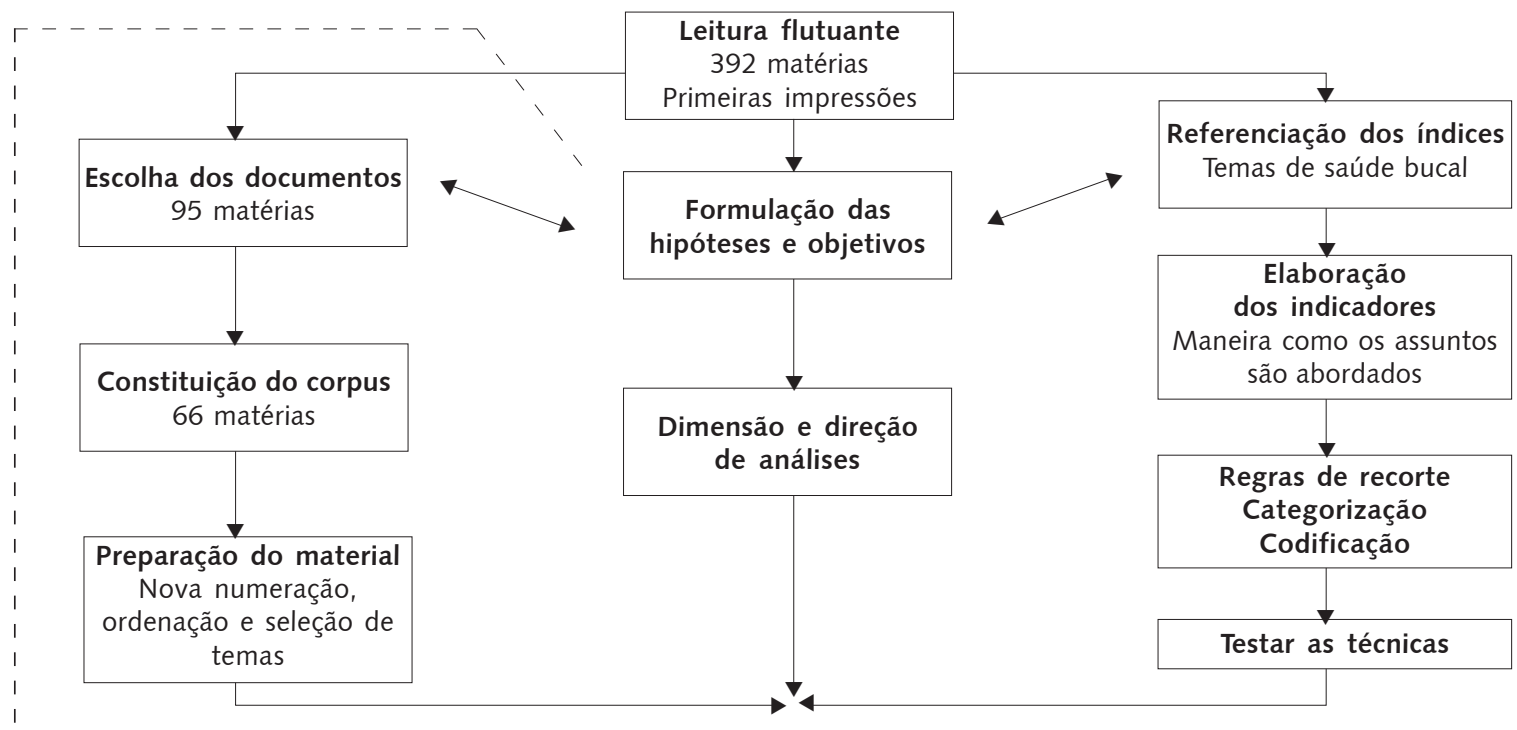

EXPLORAÇÃO DO MATERIAL

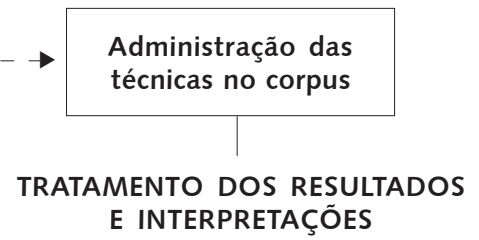

Quadro 1. Categorias, subcategorias e suas definições baseadas na análise de conteúdo das matérias dos jornais A Gazeta e A Tribuna, veiculadas no período de 2004-2009, Espírito Santo, Brasil

\begin{tabular}{|c|c|c|}
\hline Categoria & Subcategoria & Definição \\
\hline $\begin{array}{l}\text { Responsabilização do } \\
\text { indivíduo pela sua Saúde } \\
\text { Bucal }\end{array}$ & $\begin{array}{l}\text { "Você sabe escovar os dentes?" } \\
\text { "Você pode ser a maior cárie do seu dente" }\end{array}$ & $\begin{array}{l}\text { Abordagem que responsabiliza e culpabiliza o } \\
\text { indivíduo pelo seu estado de saúde bucal }\end{array}$ \\
\hline Realidades extremas & $\begin{array}{l}\text { "Pra quem pode pagar, o céu é o limite" } \\
\text { "Sem dentes e sem opção" }\end{array}$ & $\begin{array}{l}\text { Retrata realidades sociais dicotômicas em } \\
\text { relação à saúde bucal }\end{array}$ \\
\hline $\begin{array}{l}\text { Imaginário popular do } \\
\text { dentista }\end{array}$ & $\begin{array}{l}\text { Medo de dentista } \\
\text { Imaginário popular do consultório dentário }\end{array}$ & $\begin{array}{l}\text { Imagem do dentista e do tratamento dentário } \\
\text { relatada por pacientes e jornalistas }\end{array}$ \\
\hline Patologização da Halitose & $\begin{array}{l}\text { "Fantasma do mau hálito" } \\
\text { "Novas armas contra o mau hálito" }\end{array}$ & $\begin{array}{l}\text { Trata da patologização da halitose e as novas } \\
\text { tecnologias para lidar com o "problema" }\end{array}$ \\
\hline Valorização estética & $\begin{array}{l}\text { Sorriso perfeito, beleza e autoestima } \\
\text { Tecnologia a serviço da estética }\end{array}$ & $\begin{array}{l}\text { Divulga a valorização da estética bucal e as } \\
\text { novas tecnologias odontológicas }\end{array}$ \\
\hline $\begin{array}{l}\text { Determinantes da Saúde } \\
\text { Bucal }\end{array}$ & $\begin{array}{l}\text { Determinantes sociais da Saúde Bucal } \\
\text { A saúde começa pela boca? - Saúde bucal/ } \\
\text { saúde sistêmica }\end{array}$ & $\begin{array}{l}\text { Problematiza os determinantes sociais da } \\
\text { saúde e a relação saúde sistêmica-saúde bucal }\end{array}$ \\
\hline Prevenção e hábitos & $\begin{array}{l}\text { Hábitos alimentares e de higiene bucal } \\
\text { Prevenção de doenças bucais }\end{array}$ & $\begin{array}{l}\text { Discute hábitos alimentares e de higiene bucal } \\
\text { e aborda a prevenção de doenças bucais. }\end{array}$ \\
\hline
\end{tabular}




\section{Responsabilização do indivíduo}

Constataram-se, em algumas matérias, discursos de responsabilização e culpabilização do indivíduo pelo seu estado de saúde bucal, como os que seguem:

(G127a) "Você sabe escovar os dentes? [...] Todo mundo sabe que é importante escovar os dentes, mas será que todos estão alfabetizados com as lições corretas para fazer isso?"

Neste exemplo, chama atenção o pressuposto de que toda a população esteja ciente da importância da escovação dental, associado ao questionamento da existência de uma alfabetização geral sobre as boas práticas de escovação. Além disso, após considerar que o indivíduo, ao executar a técnica de forma errada, pode ficar com o "sorriso amarelo", a matéria traz uma advertência imperativa:

(G127b) "[...] Se isso acontecer, não vá botar a culpa só na coitada da escova. Segundo os dentistas, a maior 'cárie' dos dentes pode ser quem escolheu a escova na prateleira: você".

Essa abordagem "responsabilizante" com certa conotação "ameaçadora" também é discutida por Lefévre (1999), ao afirmar que, na mídia brasileira atual, verificamos a prevalência de matérias de saúde que responsabilizam o indivíduo pela "sua" saúde individual e estimulam o consumo de produtos "redutores do sofrimento" ou "melhoradores" do desempenho físico e mental. Isso gera um processo de alienação, em vez de trazer um impacto positivo.

Paralelamente, Castiel e Diaz (2007) argumentam que os discursos sobre a saúde não dizem respeito tão somente a dimensões de saúde. Outrossim, incorporam modos de pensar, escrever e abordar a saúde a partir de um contexto histórico, legitimado pela ordem econômica, política e social pelos quais são sustentados. Dessa forma, percebe-se, atualmente, a existência de discursos culpabilizantes e autoritários sobre a saúde, que se estende também à saúde bucal, em que são ressaltadas as responsabilidades individuais quanto à adoção de comportamentos saudáveis e a priorização de condutas preventivas.

Apesar do entendimento de que não se deve isentar o indivíduo das responsabilidades sobre a sua saúde e suas escolhas, uma perspectiva responsabilizante unilateral é considerada inadequada, devido ao seu caráter individualista, parcial, e pela desconsideração da complexidade dos determinantes sociais da saúde. Isso porque nem sempre a adoção de comportamentos de risco ou de situações de vida insalubres se dá por escolhas pessoais, mas, sim, por falta de opção da população e pela ausência de acesso a serviços de saúde adequados, as quais configuram as iniquidades sociais (Bydlowski, Westphal, Bicudo Pereira, 2004).

Além disso, a excessiva repetição dessa abordagem, que reforça certa culpabilização do indivíduo em relação à sua própria saúde, pode fazer com que as pessoas decidam "parar de ouvir" as questões de saúde discutidas na mídia, causando um desestímulo aos sujeitos (Xavier, 2005).

\section{Realidades extremas}

Nesta categoria, buscou-se discutir as distintas e distantes realidades sociais divulgadas pela mídia. De um lado, encontramos a expressão da parcela da população "Sem dentes e sem opção" (G155) e, de outro, é retratada a realidade de que "Para quem pode pagar, o céu é o limite" (G156). Essa dupla abordagem do tema, adotada pelo objeto de estudo, por meio de matérias consecutivas em uma mesma edição, retrata a desigualdade social em saúde presente na sociedade brasileira: (G155a) "Nunca tive condições de pagar dentista particular. Quando cheguei ao posto me disseram que o jeito era arrancar meu dente, não questionei. Depois disso, foi um atrás do outro".

Observa-se, nessa fala, o retrato de uma realidade odontológica presente em grande parcela da população, como se observa no seguinte trecho: (G155b) "[...] Como ele, outros 460 mil capixabas quase meio milhão de pessoas - vivem sem um único dente na boca". 
Dados divulgados pela Pesquisa Nacional de Saúde Bucal (Brasil, 2011) corroboram com essa afirmação, indicando que mais de três milhões de idosos necessitam de prótese total nas duas arcadas, e outros quatro milhões necessitam de prótese total em uma das arcadas (Brasil, 2011). Cabe ressaltar que a perda dentária é um dos mais graves problemas da saúde bucal dos brasileiros. Admite-se que a extração dentária representa uma atividade marcante da prática odontológica ao longo da história, todavia, constitui uma mutilação bucal, pois perder os dentes não é natural do envelhecimento e nem uma fatalidade biológica, devendo ser encarada como um problema a ser enfrentado mediante o estabelecimento de estratégias políticas e tecnologias para preservação dental adequadas (Narvai, Frazão, 2008).

A questão perpassa também um certo posicionamento acrítico da Odontologia, para deixar bem claro, da ação política de seus principais atores. Esses atores apresentam uma dificuldade de interação interdisciplinar e política, quanto ao entendimento da implicação social da Odontologia como prática, demonstrando, por exemplo, pouca capacidade de entendimento da cárie (e das doenças bucais de uma forma geral) como socialmente produzidas e determinadas. Além disso, percebe-se que o desenvolvimento científico e tecnológico da profissão acontece historicamente sem interferir muito na doença (Kovaleski, Freitas, Botazzo, 2006; Freitas, 2001).

Outro ponto embutido nessa problemática é a discriminação e as dificuldades enfrentadas pelos mutilados bucais no mercado de trabalho, como descrito a seguir:

(G156b) [...] "Ser aceito no mercado de trabalho é um desafio que os desdentados têm de enfrentar. E não é preciso ser completamente 'banguela' para se sentir excluído.

Dependendo da localização, um dente a menos pode significar a perda de emprego".

Tais flagelos, tão veiculados nos jornais, ilustram as desigualdades sociais em saúde e as iniquidades em saúde bucal. As primeiras são entendidas como as diferenças no estado de saúde entre grupos definidos por características sociais, tais como: riqueza, educação, ocupação, raça e etnia, gênero, condições do local de moradia ou trabalho (Barata, 2009). Já as iniquidades dizem respeito às diferentes distribuições de condições de saúde bucal e do acesso a bens e serviços odontológicos (Moysés, 2000).

De acordo com Moreira, Nations e Alves (2007), a condição bucal não permite apenas um registro quantitativo, mas, também, uma história vivida. Sujeitos pobres, com baixa escolaridade e menor inserção no mercado de trabalho, carregam marcas dentárias que expressam uma realidade objetiva e outra subjetiva, velada, as quais representam chagas da injustiça impressas na dentição. Ser pobre e ter aparência bucal precária amplificam as desigualdades existentes, contribuindo para a continuação do círculo vicioso do estigma e da discriminação social.

A outra face das condições bucais é abordada com base no seguinte depoimento:

(G156) "Se por um lado quem depende dos serviços públicos tem dificuldades até para manter os dentes na boca, quem pode pagar por um dentista especializado tem o céu como limite. Implantes, facetas de porcelana, clareamentos, são alguns dos recursos da odontologia estética para garantir um sorriso perfeito".

Esse determinante econômico configura o que há de mais injustamente taxativo, em se tratando de acesso a tratamento odontológico: sua (falta de) opção ou o "céu como limite", pois, quando o Estado falha no cumprimento de seu dever - o de garantir saúde à população de forma universal, igualitária e equânime -, o mercado determina a "alternativa possível" a partir de sua lógica capitalista.

\section{Imaginário popular do dentista}

Em algumas matérias analisadas, vincula-se a imagem do cirurgião-dentista e do consultório dentário à dor e ao desconforto, como se pode perceber: 
(G17) "Você já entra na sala desconfiado. Minutos depois, o dentista 'cega' seus olhos com uma luz intensa. Os pés suam frio. Na hora da anestesia, as mãos se agarram firmes no 'braço' da cadeira. Mas nada é pior do que quando ele liga aquele terrível 'motorzinho' e se aproxima com a broca".

Entende-se que o tratamento odontológico pode ser desconfortável em alguns casos, porém tais significações sociais, amplamente exploradas pela mídia, são influenciadas pelo imaginário da corporação odontológica brasileira, a partir das configurações históricas e na produção social do cirurgião-dentista e do dentista prático, herdeiros das tradições empíricas do cirurgião-barbeiro. Esses profissionais desenvolveram seus procedimentos cotidianos impregnados de conexões simbólicas e tendo como elemento dinamizador do imaginário popular o ato odontológico original: a extração dentária. Esta, quando não indicada corretamente, caracteriza-se como mutilação humana, contribuindo para a associação do tratamento dentário ao sofrimento e à angústia (Emmerich, 2000). Esse imaginário popular da figura do dentista associado ao medo e à dor é frequentemente explorado pela mídia (Henriquez, 1993), o que alimenta a perpetuação desse estigma relacionado com a Odontologia, sendo um verdadeiro flagelo para os indivíduos.

Outra questão identificada no estudo foi a divulgação do "enfrentamento" desse medo de dentista perante a motivação estética de um sorriso bonito e do uso de novas tecnologias odontológicas, como se pode notar:

(T168) "Não que o consultório dentário tenha repentinamente virado um programa prazeroso, mas como o desejo dos clientes é chegar ao sorriso ideal, é a partir dele que se inicia a consulta".

Constata-se, assim, a valorização estética e "biotecnológica" nessa divulgação midiática, priorizando a perspectiva mercadológica da Odontologia em detrimento da exploração de seu papel social.

\section{Patologização da halitose}

Os odores bucais são fatores de preocupação para os indivíduos e carregam consigo fortes valores culturais (Elias, Ferriani, 2006). A halitose, conhecida popularmente como "mau hálito" ou "bafo", representa um fenômeno que acompanha o homem na sua trajetória social-histórica e pode possuir etiologias múltiplas, tanto por razões fisiológicas, como por razões patológicas, locais ou sistêmicas, devendo todas as possíveis causas serem investigadas e o tratamento direcionado de acordo com cada causa (Emmerich, Castiel, 2012).

Contudo, identifica-se, na sociedade contemporânea, um clima paranoide de preocupação aliado a uma divulgação midiática ostensiva em relação ao "risco de estar com mau hálito" e sobre as "formas mais eficazes de preveni-lo". Neste estudo, tal questão foi identificada nos seguintes trechos:

(G21a) "Cerca de 60\% dos brasileiros convivem diariamente com ele, mas ninguém gosta de falar sobre o assunto que, muitas vezes, causa situações constrangedoras".

(T135b) "Para evitar o 'bafão' o segredo é caprichar na higiene bucal".

Verifica-se que essa inquietação quanto aos maus odores bucais é abordada a partir de uma estigmatização do mal-estar social inerente ao problema. Reflete-se, entretanto, que essa espetacularização desnecessária da questão está, subliminarmente, associada à tentativa biopolítica de tornar os sujeitos mais sociáveis e, também, à comercialização de "mercadorias" para melhor aceitação no mercado de trabalho, à autoaceitação e ao maior "conforto" social (Emmerich, Castiel, 2012).

Além disso, verificou-se a divulgação de uma gama de produtos "aliviadores das mazelas" provocadas pela halitose, como por exemplo: (G91a) "Pessoa com mau hálito pode ser avisada por e-mail [...] O nome do serviço é SOS Mau Hálito". 
É evidente que se devem buscar maneiras eficazes de tratar o desconforto provocado pela halitose, bem como identificar possíveis problemas sistêmicos que estejam provocando o mau odor bucal. Entretanto, o que se questiona são as motivações midiáticas na divulgação do controle do problema (para não afetar os relacionamentos e a ascensão social), priorizando a busca de produtos com eficácia rápida e impactos afetivos bombásticos, em vez da valorização da saúde bucal como um todo (Emmerich, Castiel, 2012). Além disso, essa patologização da halitose pode se tornar um fator de autocontrole socialmente incutido, totalmente desconexo do contexto social em que se insere o indivíduo, podendo significar "precariedades do excesso" de preocupações com o corpo, destituindo-o de características humanas, por essência, e reforçando o discurso autoritário de culpabilização do sujeito pela sua saúde (Castiel, Diaz, 2007; Castiel, Vasconcellos-Silva, 2006).

\section{Valorização estética}

Verificou-se, a partir dos resultados, uma acentuada valorização midiática da estética do sorriso, como se confere nos trechos seguintes:

(G74) "[...] Ter um sorriso perfeito é hoje quase uma obrigação no meio social e no mercado de trabalho".

(T84) "Em busca do sorriso perfeito [...] A busca por um sorriso perfeito tem levado mais pacientes aos consultórios de dentistas do que cáries, canais e dores de dentes".

Além disso, percebeu-se a menção explícita da prescrição midiática da busca de "saber estético" especializado, assim como a exaltação dos custos de um belo sorriso, como se vê a seguir:

(G156) "A gerente de vendas ' $X$ ' se orgulha de exibir um sorriso perfeito. E não era para menos. Nos últimos anos, ela gastou mais de $\mathrm{R} \$ 10$ mil para ficar com os dentes bonitos $\mathrm{e}$ branquinhos".

Essa divulgação midiática ostensiva de questões estéticas reflete os valores sociais relacionados aos desejos e vaidades, os quais contribuem para a produção de um padrão estético utópico e de uma Odontologia sem fronteiras, sem crises nem recessão econômica, com mercado aberto e crescente (Emmerich, Castiel, 2009a; Amorim, Beatrice, Vicente da Silva, 2006). Percebe-se que até mesmo o nome fantasia "Brasil Sorridente", da Política Nacional de Saúde Bucal (Brasil, 2004), caracteriza simbolicamente o "sorriso" como um elemento da saúde bucal, mas pode contribuir para fomentar o imaginário da aparência estética facial idealizada.

Além disso, o direcionamento midiático, com extrema valorização consumista, aos potenciais clientes de tratamentos estéticos odontológicos, perpetua a imagem do objeto odontológico de seus sonhos - perfeito, extraordinário, "global ou hollywoodiano" -, levando à procura de cirurgiõesdentistas (muitas vezes anunciados na própria mídia) com essa demanda estética estereotipada.

\section{Tecnologias a serviço da estética}

Em relação às biotecnologias odontológicas, a mídia também contribui na sua divulgação e, consequentemente, pauta na sociedade a demanda (real ou não) de tratamentos odontológicos cada vez mais "modernos" e "tecnólogo-dependentes", como sugerido nos trechos abaixo:

(T136a) "Tecnologia a serviço do sorriso [...] Novas técnicas e a evolução dos materiais ajudam os profissionais da odontologia a garantirem sorrisos mais perfeitos".

(T136b) "Se depender dos avanços tecnológicos e da evolução técnica da odontologia brasileira, não há mais boca sem salvação". 
A influência midiática no consumo e nos valores estéticos da população pode ser entendida por meio do modelo teórico de mercado simbólico, desenvolvido por Araújo (2004), no qual se admite que a comunicação opera à maneira de um mercado, em que estão presentes múltiplos e heterogêneos discursos que disputam o poder de fazer prevalecer determinada visão da realidade. Dessa forma, mediante a propaganda e a publicidade implícitas no conteúdo midiático, difundem-se determinados discursos (no caso, o estético-dependente) em detrimento de outros (que problematizam a saúde integral, por exemplo), constituindo-se hegemonias de sentidos, sobre modos de vir e intervir na realidade (Rangel-S, 2007). Nesse caso, parafraseando Castiel e Vanconcellos-Silva (2006), convertemse excessos em escassez, na ausência de sentidos. No caso, excesso de estética em escassez de percepção crítica das reais demandas em saúde bucal.

\section{Determinantes da saúde bucal}

Os resultados apresentados nessa categoria foram divididos em subcategorias relacionadas aos determinantes sociais da saúde bucal e à relação entre saúde geral e saúde bucal.

Os determinantes sociais da saúde são os fatores sociais, econômicos, culturais, étnico/raciais, psicológicos e comportamentais que influenciam a ocorrência de problemas de saúde e seus fatores de risco na população, segundo a Comissão Nacional sobre os Determinantes Sociais da Saúde (CNDSS) (Buss, Pellegrini Filho, 2007). Entende-se que os problemas de saúde bucal estão para além das questões fisiológicas, sendo também determinados por questões sociais, devendo se considerar, além dos dados epidemiológicos, os aspectos de natureza sociocultural e antropológica que determinam as atitudes em saúde bucal da população (Moreira, Alves, 2006). Os seguintes trechos contextualizam essa discussão:

(G147) "A cárie e o jeito de morar [...] Quem diria...o surgimento da cárie dentária na infância também está atribuído a fatores sociodemográficos, como o número de pessoas por quarto de dormir".

(G156) "Como priorizar a saúde bucal quando não se tem nem o que comer direito?"

Essa articulação do adoecer bucal com as condições sociais da existência foi discutida nas Conferências Nacionais de Saúde Bucal (CNSB). No relatório da $3^{a}$ CNSB foi apresentada a análise de que as imagens do corpo humano, dentre elas as da boca e dos dentes, são expressões e símbolos da chaga da exclusão social. Seja pelos problemas de saúde localizados na boca, seja pela dificuldade de acesso aos serviços assistenciais, dentes e gengivas revelam o resultado das condições de vida precárias de milhões de pessoas em nosso país (Brasil, 2005).

Outro trecho representativo, referente ao determinante social relacionado ao ambiente em que a pessoa vive e a saúde bucal, é assim descrito:

(G45) "No caso dos capixabas, principalmente os moradores da área urbana da grande Vitória, o respirador oral sofre ainda mais. Isso porque essa é uma região muito poluída, com grande incidência de pó de minério vindo das fábricas".

Entende-se que o local de moradia (tomando o espaço geográfico como indicativo de condições de vida da população que nela reside) e os fatores ambientais (urbanização, poluição atmosférica e dos corpos hídricos) também influenciam nos eventos de saúde e, consequentemente, de saúde bucal (Brasil, 2008). Em um contexto mais amplo, a posição social dos indivíduos e grupos sociais, medida por indicadores de classe social, como escolaridade e classes ocupacionais, ou a partir das condições de vida em determinados espaços geográficos, são poderosos determinantes do estado de saúde das populações, atuando sobre o perfil de morbidade e de mortalidade e também sobre o acesso e utilização dos serviços de saúde (Barata, 2009). Nesse contexto, percebe-se uma abordagem bem fundamentada da mídia, uma vez que as matérias apontam fatores que estão para além da responsabilidade individual, ou seja, as questões geográficas e ambientais que interferem diretamente no processo de adoecimento do cidadão. 


\section{Saúde bucal/saúde sistêmica}

Sabe-se da estreita relação da saúde bucal com a saúde geral dos indivíduos. Entretanto, a prática odontológica não exercita uma interdisciplinaridade, expondo seus limites de compreensão dos fatores externos à boca, sobretudo no que diz respeito aos determinados ou potencializados pela sociedade (Kovaleski, Freitas, Botazzo, 2006). Sendo assim, os fragmentos seguintes problematizam essa questão:

(G54) "Tem-se o péssimo hábito de desvincular a boca do resto do corpo".

(G56) "Falta de cuidado com a boca afeta saúde".

(G156b) "A saúde começa pela boca".

Ampliando essa discussão, o conceito de bucalidade expande o entendimento da "boca" como um órgão da fala e da mastigação, desvendando suas expressões sociais, como: a manducação (apreensão, trituração, salivação e deglutição dos alimentos), a linguagem e a erótica (Botazzo, 2006). Revela, então, que a boca não se encontra isolada, mas, sim, que esta compõe um corpo conformado de dimensões biológicas, psíquicas e afetivas. Isso reforça a necessidade de uma prática odontológica não alienada que dê conta da boca como objeto coletivo.

Portanto, ao se analisar o discurso midiático de que "a saúde começa pela boca", recomenda-se parcimônia e olhar crítico, para não se incorrer num distanciamento e na fragmentação da percepção do objeto odontológico. Isso porque, uma vez que, ao se considerar que a cavidade bucal seria "onde tudo começa" no processo saúde-doença, a integralidade da saúde, as relações intersubjetivas entre os indivíduos e as condições socioeconômicas, amplamente discutidas neste trabalho, poderiam ser colocadas em segundo plano na problematização da questão (Emmerich, Castiel, 2009b).

\section{Prevenção e hábitos}

Questões relacionadas aos hábitos de higiene e alimentares e à prevenção das doenças bucais foram destacadas no estudo, como se pode atestar:

(G131) "Arroz e feijão podem prevenir cárie [...] O consumo dos alimentos proporciona dose diária de flúor, que ajuda no controle da doença".

(G169) "A cárie de mamadeira está relacionada, também, com outros hábitos introduzidos pelas mães, como por exemplo, chupetas com mel, açúcares e xaropes, e o uso da mamadeira por tempo prolongado".

(G127) "Questão de hábito. Não basta usar a escova. Para preservar os dentes, é preciso higienizar do jeito certo".

Percebe-se, nos textos jornalísticos, a preconização da adoção de hábitos de higiene e de alimentação ideais, de acordo com o conhecimento científico, aliado a uma responsabilização do indivíduo na adoção de condutas preventivas. Essa abordagem preventiva está presente na atuação histórica da Odontologia e da saúde como um todo, tendo importância capital na manutenção da saúde bucal da população (Freitas, 2001). Contudo, ao se indicarem hábitos de higiene e alimentares dirigidos à população, deve-se considerar a questão do papel das estruturas sociais na determinação das escolhas subjetivas pelas possibilidades objetivas, as quais representam, segundo Bourdieu (1996), o principal fomentador de estilos de vida e de consumo. Sendo assim, almeja-se, do jornalismo, um modo inteligente e criativo de informar a sociedade, uma vez que uma relação "professoral" mídia-população, descontextualizada de suas demandas, de suas crenças e saberes populares em saúde bucal, determina uma comunicação arbitrária e ineficiente (Xavier, 2005). 
Nessa acepção, a matéria que privilegia práticas alimentares triviais, como o consumo do arroz e feijão, que se configura como a dieta básica da maioria dos brasileiros, denota uma sensibilidade do discurso jornalístico com o contexto socioeconômico da população. Também é importante salientar que reportagens que apontam hábitos equivocados e que podem comprometer a saúde trazem significantes contribuições para a prevenção e a promoção da saúde bucal, desde que problematizados de maneira crítica. A divulgação midiática da prevenção na saúde bucal teve destaque, ainda, nas seguintes falas:

(G79) "A palavra-chave na odontologia é prevenção".

(T11) "Dentistas defendem que, mesmo com amostras de maior eficácia em cremes dentais, o principal para evitar as cáries é a escovação".

A Política Nacional de Saúde Bucal (PNSB) contém diretrizes que apontam para a reorganização da atenção à saúde bucal em todos os níveis de atenção. Dentre suas ações efetivas de promoção da saúde e prevenção, propõe a articulação com diversos atores sociais na identificação e difusão de informações sobre fatores de proteção à saúde (Brasil, 2004). Ressalta-se o significativo papel da mídia, mediante seu potencial de pautar o tema saúde bucal no cotidiano da população (Wolf, 1999), propagar essas informações relevantes por intermédio de seu potencial educativo (Gentilli, 2005) e de influenciar a opinião pública. Cria, assim, uma doxa coletiva, entendida como uma opinião consensual, a qual é permanentemente reestruturada e construída na sociedade pelos meios de comunicação (Xavier, 2006).

No entanto, para que a mídia exerça esse papel educativo de maneira efetiva, deve-se atentar para que o discurso adotado não determine uma "mercadorização" do cuidar de si, sob o imperativo da autorresponsabilização da saúde, uma vez que o papel dos governos, das empresas e da sociedade, na prevenção e na promoção da saúde, deve ser também considerado (Vasconcellos-Silva et al., 2010).

\section{Considerações finais}

A compreensão de como as matérias sobre saúde bucal são divulgadas na mídia impressa capixaba perpassou a problematização de diversos fatores sociais, culturais, políticos, biológicos e econômicos. Tal rede, multifatorial, destaca a determinação social como fator peremptório da saúde bucal, constatandose, assim, a importância de se buscar uma comunicação midiática que considere essas dimensões sóciohistóricas na abordagem da temática.

Além disso, pôde-se refletir e concluir que a mídia, ao veicular uma valorização estética exacerbada, perpetua um mercado simbólico centrado nos desejos e vaidades, ancorados numa filosofia consumista, que não só distancia a percepção do objeto odontológico como um objeto coletivo e determinado socialmente, como também fomenta, no imaginário popular, uma demanda estética utópica descontextualizada das reais necessidades e possibilidades da saúde da população como um todo.

Dessa forma, almeja-se uma divulgação midiática que exerça sua potência de educação e promoção da saúde bucal de forma interativa e dialógica, considerando as diversas realidades existentes naquele contexto social e incitando a conscientização crítica dos indivíduos, em vez de responsabilizá-los e culpabilizá-los pela sua saúde. O discurso midiático poderia, assim, contribuir para uma conscientização do indivíduo, fundamentando-se nos princípios da corresponsabilidade, sendo o cidadão e o Estado corresponsáveis pela promoção da saúde para que se possa estabelecer uma relação de alteridade. Além disso, espera-se um esclarecimento popular sobre a assistência pública de saúde bucal no SUS, o acesso e a organização desses serviços no estado do Espírito Santo e no Brasil.

Cabe ressaltar que, como assevera Foucault (2007), o poder é exercido por meio das microrrelações sociais presentes em instituições, como a escola, a família, a religião e a mídia. No entanto, onde há poder há resistência, sendo cada um de nós titular de determinado poder e, portanto, 'veiculador' desse poder. Nesse sentido, as relações interativas entre os sujeitos desenvolvem suas estratégias de exercício de tal poder em prol de suas necessidades, de suas opiniões e de seus desejos, podendo se contrapor à mídia em seus interesses. 
Portanto, para garantir a qualidade das informações em saúde bucal, torna-se indispensável o aprimoramento de um olhar crítico da sociedade para a divulgação midiática, assim como também se faz necessário que se exerça um controle social efetivo na luta por uma comunicação em saúde contextualizada e em conformidade com os interesses sociais. Afinal, o comprometimento com uma comunicação em saúde de qualidade exige, basicamente, coragem para encontrar soluções, e não, simplesmente, se apontarem culpados.

\section{Colaboradores}

Aline Guio Cavaca responsabilizou-se pela coleta, análise e interpretação do material empírico e pela redação do artigo. Victor Gentilli responsabilizou-se pela análise e interpretação dos dados e pela revisão crítica e aprovação da versão final do artigo. Eliana Martins Marcolino responsabilizou-se pela revisão crítica e pela aprovação da versão final do artigo, e Adauto Emmerich responsabilizou-se pela análise e interpretação dos dados, revisão crítica e aprovação da versão final do artigo.

\section{Referências}

AMORIM, C.C.S.; BEATRICE, L.C.S.; VICENTE DA SILVA, C.H. Influência da mídia televisiva sobre o padrão estético odontológico. Odont. Clín.-Científ., v.5, n.2, p.163-6, 2006.

ARAÚJO, I. Mercado simbólico: um modelo de comunicação para políticas públicas. Interface - Comunic. Saude, Educ., v.8, n.14, p.165-78, 2004.

AZEVEDO, L. et al. Recuperação de Informação através do processo de aproximações Sucessivas. In: CONGRESSO BRASILEIRO DE BIBLIOTECONOMIA, DOCUMENTAÇÃO E CIÊNCIA DA INFORMAÇÃO, 21., 2005, Curitiba. Anais... Curitiba, 2005. 1 cd-rom.

BARATA, R. Como e por que as desigualdades sociais fazem mal à saúde. Rio de Janeiro: Ed. Fiocruz, 2009.

BARDIN, L. Análise de conteúdo. Lisboa: Edições 70, 2009

BOTAZZO, C. Sobre a bucalidade: notas para a pesquisa e contribuição ao debate. Cienc. Saude Colet., v.11, n.1, p.7-17, 2006.

Da arte dentária. São Paulo: Hucitec/Fapesp, 2000.

BOURDIEU, P. Razões práticas: sobre a teoria da ação. São Paulo: Papirus, 1996.

BRASIL. Ministério da Saúde. Projeto SB Brasil 2010: resultados principais. Brasília, 2011. Disponível em: <http://189.28.128.100/dab/docs/geral/ projeto_sb2010_relatorio_final.pdf>. Acesso em: 30 jun. 2012.

Comissão Nacional Sobre Determinantes Sociais da Saúde. As causas sociais das iniqüidades em saúde no Brasil - relatório final. Brasília, 2008. Disponível em: <http://www.cndss.fiocruz.br/pdf/home/relatorio.pdf>. Acesso em: 30 jun. 2012.

$3^{a}$ Conferência Nacional de Saúde Bucal. Saúde Bucal: acesso e qualidade, superando a exclusão social. Relatório final. Brasília: Ministério da Saúde, 2005. $\overline{M S}, 2004$

Ministério da Saúde. Diretrizes da Política Nacional de Saúde Bucal. Brasília:

BUSS, P.M.; PELLEGRINI FILHO, A. A saúde e seus determinantes sociais. Physis, v.17, n.1, p.77-93, 2007. 
BYDLOWSKI, C.R.; WESTPHAL, M.F.; BICUDO PEREIRA, I.M. Promoção da saúde. Porque sim e porque ainda não! Saude Soc., v.13, n.1, p.14-24, 2004.

CARVALHO, M.B.; BICUDO PEREIRA, I.M.T. O jornal e a educação em saúde bucal. Rev. Bras. Saude Esc., v.3, n.1-4, p.39-43, 1994.

CASTIEL, L.D.; DIAZ, C.A.D. A saúde persecutória: os limites da responsabilidade. Rio de Janeiro: Ed. Fiocruz, 2007.

CASTIEL, L.D.; VASCONCELLOS-SILVA, P.R. Precariedades do excesso: informação e comunicação em saúde coletiva. Rio de Janeiro: Ed. Fiocruz, 2006.

CAVACA, A.G. Análise das matérias de saúde bucal veiculadas na mídia impressa no Espírito Santo, nos anos de 2004 a 2009. 2011. Dissertação (Mestrado) - Programa de Pós-graduação em Saúde Coletiva, Universidade Federal do Espírito Santo, Vitória. 2011.

CAVACA, A.G. et al. A saúde bucal na mídia impressa: análise das matérias jornalísticas nos anos de 2004-2009. Cienc. Saude Colet., v.17, n.5, p.1333-45, 2012.

ELIAS, M.S.; FERRIANI, M.G.C. Historical and social aspects of halitosis. Rev. Latino-Am. Enfermagem, v.14, n.5, p.821-3, 2006.

EMMERICH, A. A corporação odontológica e o seu imaginário. Vitória: Edufes, 2000.

EMMERICH, A.; CASTIEL, L.D. Mais humano que um humano: a halitose como emblema da patologização odontológica. Cienc. Saude Colet., v.17, n.1, p.89-98, 2012.

Jesus tem dentes metal-free no país dos banguelas?: odontologia dos desejos e das vaidades. Hist., Cienc., Saude - Manguinhos, v.16, n.1, p.95-107, 2009a.

A ciência odontológica, sísifo e o "efeito camaleão'. Interface - Comunic. Saude, Educ., v.13, n.29, p.339-51, 2009 b.

FOUCAULT, M. Microfísica do poder. 23.ed. São Paulo: Graal, 2007.

FREITAS, S.F.T. História social da cárie dentária. Bauru: Edusc, 2001.

GENTILLI, V. Democracia de massas: jornalismo e cidadania. Porto Alegre: Edipucrs, 2005.

HENRIQUEZ, V.E.P. Veiculação de informações sobre saúde bucal: 1980-1991. 1993. Dissertação (Mestrado em Odontologia) - Curso de Pós-Graduação em Odontologia, Universidade Federal Fluminense, Niterói. 1993.

HERSCOVITZ, H.G. Análise de conteúdo em jornalismo. In: LAGO, C.; BENETTI, M. (Orgs.). Metodologia de pesquisa em jornalismo. Petrópolis: Vozes, 2007. cap.2. p.123-42.

KOVALESKI, D.F.; FREITAS, S.F.T.; BOTAZZO, C. Disciplinarização da boca, a autonomia do indivíduo na sociedade do trabalho. Cien. Saude Colet., v.11, n.1, p.97-103, 2006.

LEFÉVRE, F. A saúde como fato coletivo. Saude Soc., v.8, n.2, p.83-91, 1999.

MINAYO, M.C.S. O desafio do conhecimento: pesquisa qualitativa em saúde. 11.ed. São Paulo: Hucitec, 2008.

MOREIRA, T.P.; NATIONS, M.K.; ALVES, M.S.C.F. Dentes da desigualdade: marcas bucais da experiência vivida na pobreza pela comunidade do Dendê, Fortaleza, Ceará, Brasil. Cad. Saude Publica, v.23, n.6, p.1383-92, 2007.

MOREIRA, T.P.; ALVES, M.S.C.F. Saúde Bucal e desigualdades: dos números à experiência das doenças no cotidiano. In: DIAS, A.A. (Org.). Saúde bucal coletiva: metodologia de trabalhos e práticas. São Paulo: Ed. Santos, 2006. p.261-96. 
MOYSÉS, S.J. Desigualdades em saúde bucal e desenvolvimento humano: um ensaio em preto, branco e alguns tons de cinza. Rev. Bras. Odont. Saude Colet., v.1, n.1, p.119, 2000.

NARVAI, P.C.; FRAZÃO, P. Saúde bucal no Brasil: muito além do céu da boca. Rio de Janeiro: Ed. Fiocruz, 2008.

NOGUEROL, B. et al. Analysis of oral health information in the Spanish mass media. Comm. Dent. Oral Epidemiol., v.20, n.1, p.15-9, 1992.

RANGEL-S, M.L. Comunicação no controle de risco à saúde e segurança na sociedade contemporânea: uma abordagem interdisciplinar. Cienc. Saude Colet., v.12, n.5, p.1375$1385,2007$.

ROZEMBERG, B. Comunicação e participação em saúde. In: CAMPOS, G.W. S. et al. (Orgs.). Tratado de Saúde Coletiva. São Paulo: Hucitec, 2006. p.741-66.

SHOEMAKER, P.J.; REESE, S.D. Mediating the message, theories of influences on mass media content. 2.ed. White Plains: Longman, 1996.

SINHORINI, P.A.; GARBIN, C.A.S.; OLIVEIRA, R.N. O caráter educativo de artigos relacionados à odontologia selecionados da mídia voltada ao público em geral.

Rev. Paul. Odont., v.27, n.3, p.11-3, 2005.

TOBAR, F.; YALOUR, M.R. Como fazer teses em saúde pública: conselhos e idéias para formular projetos e redigir teses e informes de pesquisas. Rio de Janeiro: Ed. Fiocruz, 2001.

VASCONCELLOS-SILVA, P.R. et al. As novas tecnologias da informação e o consumismo em saúde. Cad. Saude Publica, v.26, n.8, p.1473-82, 2010.

WOLF, M. Teorias da comunicação. 5.ed. Lisboa: Presença, 1999.

XAVIER, C. Mídia e saúde, saúde na mídia. In: SANTOS, A. (Org.). Caderno Mídia e Saúde Pública. Belo Horizonte: Escola de Saúde Pública/Funed, 2006. p.43-55.

Que saúde? Os três argumentos: mídia, saúde e comunicação. In: CONFERÊNCIA BRASILEIRA DE COMUNICAÇÃO E SAÚDE - COMSAÚDE, 8., 2005, Rio Grande do Sul. Trabalho apresentado... Rio Grande do Sul, 2005. Disponível em: <http:// www.projetoradix.com.br/arq_artigo/VII_45.htm>. Acesso em: 30 jun. 2012.

CAVACA, A.G. et al. Las representaciones de la Salud Bucal en los medios impresos. Interface - Comunic., Saude, Educ., v.16, n.43, p.1055-68, out./dez. 2012.

Fue realizada una investigación qualitativa para entender como las informaciones sobre la Salud Bucal son difundidas por los medios de comunicación impresos en el estado del Espírito Santo - Brasil, utilizando análisis del contenido de 66 reportajes publicados de marzo 2004 a junio 2009, en los periódicos A Gazeta e A Tribuna. Los materiales empíricos originaron siete categorias: responsabilización del indivíduo, realidades extremas, imaginario popular del dentista y de consultorio, su patología de la halitosis, valoración estética, determinantes de la salud bucal, prevención y hábitos. El planteamiento em los medios de comunicación de la salud bucal tiene una complejidad de factores sociales, culturales, políticos, biológicos, económicos, que pone de relieve la importancia de una comunicación contextuada con los intereses de la sociedad, interactiva y dialógica que explore su potência crítica en la educación y promoción de la salud, transmitiendo de manera consciente el consumismo en Salud Bucal.

Palabras clave: Salud Bucal. Comunicación en salud. Medios de comunicación de masas. Salud Pública.

Recebido em 02/11/11. Aprovado em 20/06/12. 